\title{
Cephalometric Appraisal of Antero-posterior Skeletal Discrepancỵ: An Overview
}

\author{
Dr Suchita Tarvade Daokar,' Dr Raksha Rajput² \\ Professor, 2PG Resident, Dept of Orthodontics, CSMSS Dental College, Aurangabad, India
}

Correspondence: Dr Suchita Tarvade Daokar; Email: suchitadaokar@gmail.com

\section{ABSTRACT}

Cephalometry is one of the important diagnostic tools for assessment of jaw relationship. Sagittal jaw relationship is of utmost concern to the patients and orthodontist. Many linear and angular parameters are used for measurement of sagittal jaw discrepancies. This article reviews various AP cephalometric parameters.

\section{INTRODUCTION}

There are various methods used in orthodontics for treatment planning which includes clinical examination, model analysis, various radiographs like OPG, lateral cephalogram, PA cephalogram. Cephalometric is one of the important diagnostic tools for assessment of jaw relationship in all three planes: sagittal, vertical and transverse. There have been many parameters introduced for evaluation of sagittal and vertical discrepancies. Antero-posterior jaw relationship is of utmost concern in evaluating the type of skeletal pattern.

Angular and linear parameters along with the cranial reference planes such as Frankfort horizontal plane and Sella-Nasion plane have been used for the measurement of sagittal discrepancies. ANB angle, Wits appraisal, ${ }^{2} \mathrm{~W}$ angle, ${ }^{3}$ Beta angle, ${ }^{4}$ Yen angle, ${ }^{5} \mathrm{HBN}$ angle ${ }^{6}$ and SAR angle ${ }^{7}$ have been defined for sagittal jaw relationship. Each of these parameters has their own advantages and drawbacks. This review article briefly describes these parameters in chronological order of their discovery and their use in orthodontics.

\section{Antero-posterior dysplasia ${ }^{8}$}

Introduced by: Wendel L. Wylie (1947)

First parameter of antero-posterior discrepancies measured quantitatively in millimeters. Mandibular length was measured by dropping the perpendicular from posterior point of condyle, and pogonion to lower border of the mandible.

Sample: Subjects of growing age (11.5 years).

Mean value of maxillary length: Class I: $52 \mathrm{~mm}$, Class
II: Value above normal (negative sign), Class III: Value below normal (positive sign).

Disadvantage: Data obtained from samples of growing age may differ from adults. Also the linear measurements are more prone to errors than angular.

\section{2. $A B$ plane angle and Angle of Convexity}

Introduced by: William B. Downs (1948)

First angular measurement for antero-posterior discrepancies. Angle of convexity (Nasion-Point A-Pogonion) gives the measure of protrusion of maxillary part of the face to the total profile. Location of $A B$ plane angle with facial plane is the measure of anterior limit of the denture bases with each other and facial profile.

Sample: 20 subjects (mean age 12-17 years).

Mean value: Angle of Convexity: Considered negative if Point A falls behind the facial plane

and positive if it is ahead; normal range $+10^{\circ}$ to $-8.5^{\circ}$.

A-B plane angle: $0^{\circ}$ to $-9^{\circ}$.

Disadvantage: As the facial type is known to differ racially this study is limited to White race.

\section{Angle ANB}

Introduced by: Richard A Riedell (1952), later Cecil C Steiner10 in 1953 used this analysis. Most widely accepted for evaluating antero-posterior jaw relationships. ${ }^{11-13}$

Sample: 52 (24 children, 28 adults) aged between 1836 years in Washington population.

Disadvantage: Difference found between the interpretation of this angle and actual discrepancy 


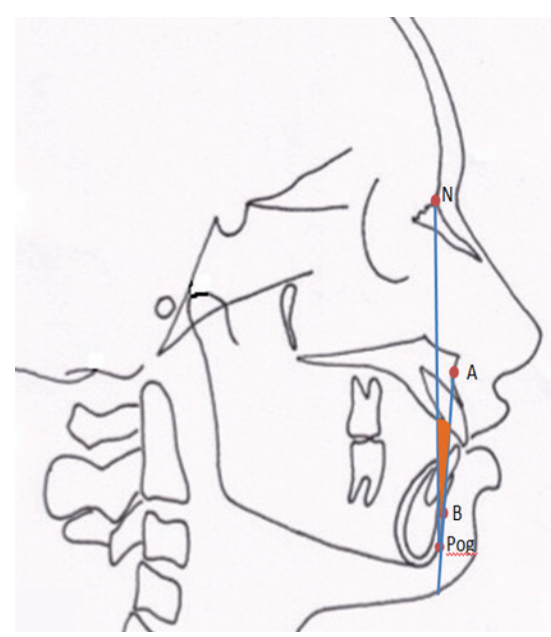

Figure $1 A$. $A B$ plane angle

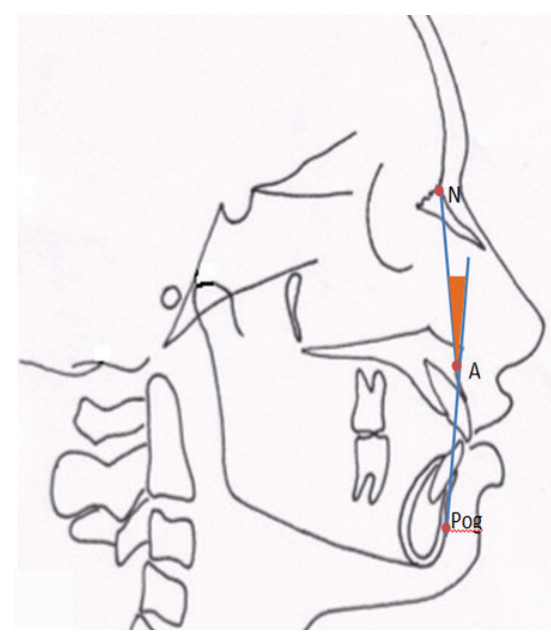

Figure 1B. Angle of convexity

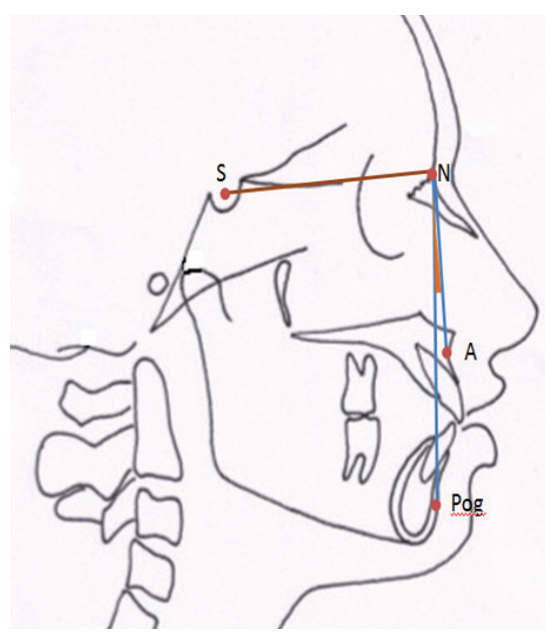

Figure 2: ANB Angle between the apical bases. Several studies ${ }^{11,14-16}$ showed it is due to Nasion point; which is not fixed during growth that affects ANB angle. Rotation of the jaws due to growth or orthodontic treatment also change ANB angle. The length of cranial base, anterior facial height also affects ANB angle. ANB angle decreases due to counter clockwise rotation of the mandible with advancing age. ${ }^{17}$

\section{Jenkin's 'A' plane ${ }^{18}$}

Introduced by: David H. Jenkin (1955)

Uses occlusal plane as a reference plane. 'A' plane was dropped perpendicular to occlusal plane from point $A$.

Sample: 180 individuals with thirty in each group of $3,6,8,12,22$ years.

Mean value: Linear distance from ' $A$ ' plane to Point B ( $+3 \mathrm{~mm})$, Gnathion ( $+5 \mathrm{~mm})$ and mandible $(+2 \mathrm{~mm})$ incisors is measured for the identification of dysplasia.
Advantage: The resultants of all components of force in the masticatory area are expressed about the occlusal plane. Thus, its behavior reflects the sum of all influences acting on this area. Since the teeth form the occlusal plane, this is the only plane to which the teeth of each jaw are intimately related. The occlusal plane is the plane of reference of the Angle Classification 1 and Baume Classification.?

Disadvantage: Normally, it is not a plane, but a complex curve; which is very difficult to define. In any case, it cannot be reliably drawn and a tracing cannot be reliably repeated.

\section{Taylor's AB' linear distance ${ }^{12}$}

Introduced by: CM Taylor (1969)

The linear distance between Point A and B'. Point B' is the perpendicular from Point $B$ to Sella-Nasion plane. There was $1 \mathrm{~mm}$ change from Point $B$ ' to ' $A$ ' with each degree of change in ANB angle.

Mean value: $13.2 \mathrm{~mm}$.

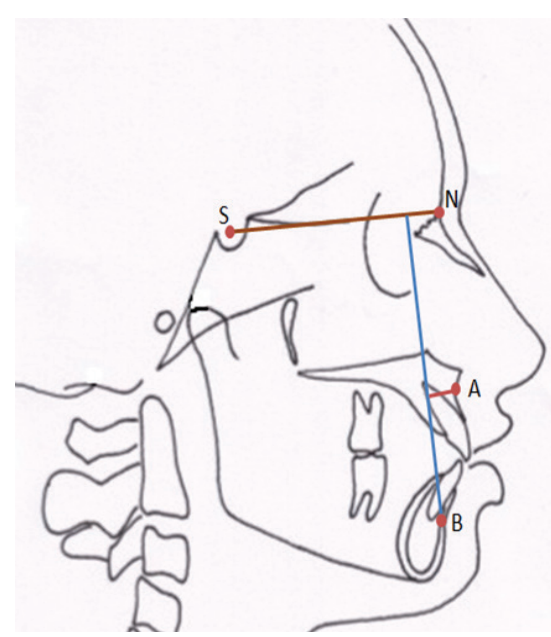

Figure 3: Taylor's AB' linear distance

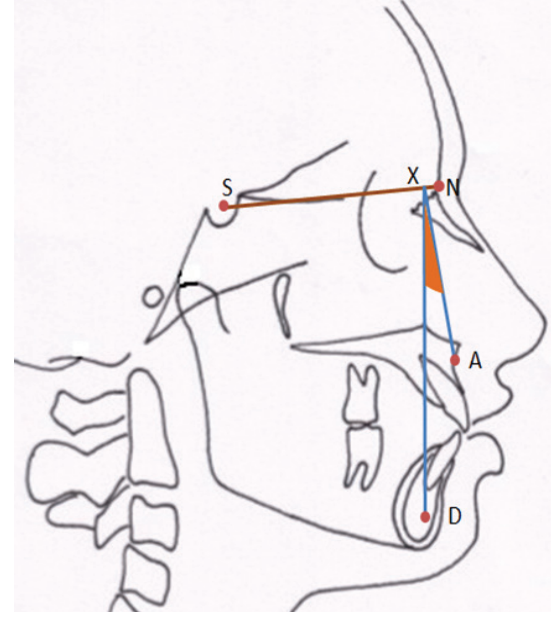

Figure 4: AXD Angle and AD' Distance

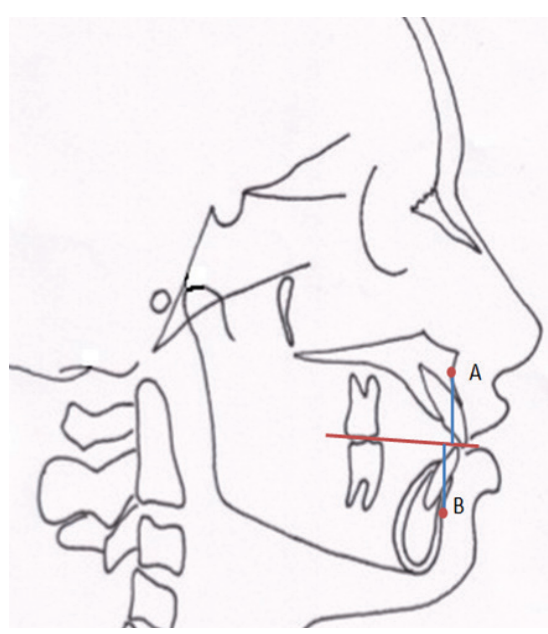

Figure 5: Wits Appraisal 


\section{6. $A X D$ angle and $A D^{\prime 19}$}

Introduced by: Edward Beatty (1975)

AXD angle is the interior angle formed by the intersection of lines extending from Point $A$ and $D$ to point $X$ ( $X$ is the perpendicular line from Point $A$ dropped on SN plane). $A D^{\prime}$ linear measurement is from Point $A$ to line DD' as $A-D^{\prime}$ ( $D^{\prime}$ is the perpendicular from $D$ to Sella-Nasion plane).

Mean value: AXD angle: $9.3^{\circ}, \mathrm{A}^{-D^{\prime}}$ distance: $15.5 \mathrm{~mm}$. Advantage: Uses Point $D$ which is not affected by the changes in incisor position and chin prominence. It also eliminates Nasion point.

Disadvantage: Point A is still used, which is affected by orthodontic tooth movement.

\section{Wit's Appraisal of jaw disharmony ${ }^{2}$}

Introduced by: Alex Jacobson (1975)

Overcomes the shortcomings of ANB angle. Perpendiculars from Point $A$ and $B$ on the maxilla and mandible, respectively, are drawn onto the occlusal plane. The points of contact are labelled $\mathrm{AO}$ and $\mathrm{BO}$, respectively.

Sample size: 46 (21 males and 25 females).

Mean value: Class I: $\mathrm{BO}$ coincides with $\mathrm{AO}$ in females, $\mathrm{BO}$ is $1 \mathrm{~mm}$ ahead of $\mathrm{AO}$ in males. Class II: $\mathrm{BO}$ positioned well behind point $\mathrm{AO}$ (positive reading), Class III: $\mathrm{BO}$ positioned ahead of point $\mathrm{AO}$ (negative reading).

Advantage: Samir Bishara et $a^{20}$ showed that Wits value does not change with age.

Disadvantage: It uses occlusal plane, which is a dental parameter to describe skeletal jaw discrepancies. Occlusal plane can be easily affected by tooth eruption or by orthodontic tooth movement.21-23 Accurate identification of occlusal plane is not easy or accurately reproducible..$^{24,25}$

\section{Antero-posterior Dysplasia Indicator (APDI) ${ }^{26}$}

Introduced by: Kim YH and Vietas JJ (1978)

The APDI reading is obtained by tabulating the facial angle (FH to NPog) plus or minus the A-B plane angle ( $A B$ to NPog) and plus or minus the palatal plane angle (ANS-PNS to $\mathrm{FH}$ plane).

Sample: 102 children with normal occlusion and 874 children with various malocclusions.

Mean value: 81.40 (SD 3.79). Lesser value indicates disto-occlusion, greater value indicates mesioocclusion.

\section{Freeman's AXB angle (1981) 11}

Introduced by: Robert S. Freeman (1981)

A perpendicular is drawn from Point $A$ to the Frankfort horizontal establishing Point $X$. A line from Point $X$ to Point B forms A-X-B angle.

Mean value: Approximately $4^{\circ}$. A variation to this is to draw perpendicular from point A to SN plane (X point), giving an angle of $6.5^{\circ}$.

Disadvantage: Factors such as steepness of SN plane, variation in Point A due to root position (as in Class II Div Il cases), excessively long or short faces, exceptionally large or short mandible are not mentioned.

\section{JYD Angle (1982) ${ }^{27}$}

Introduced by: S. Jarvinen

Formed by intersection of line from Point $J$ and $D$ to Point $Y$.

Mean value: $5.25 \pm 1.97^{\circ}$

Advantage: Eliminates Point A.

Disadvantage: JYD angle affected by jaw growth and vertical facial growth.

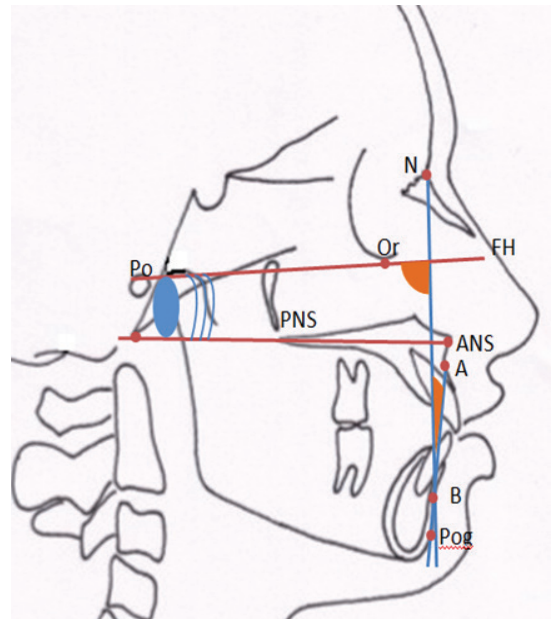

Figure 6: APDI angle

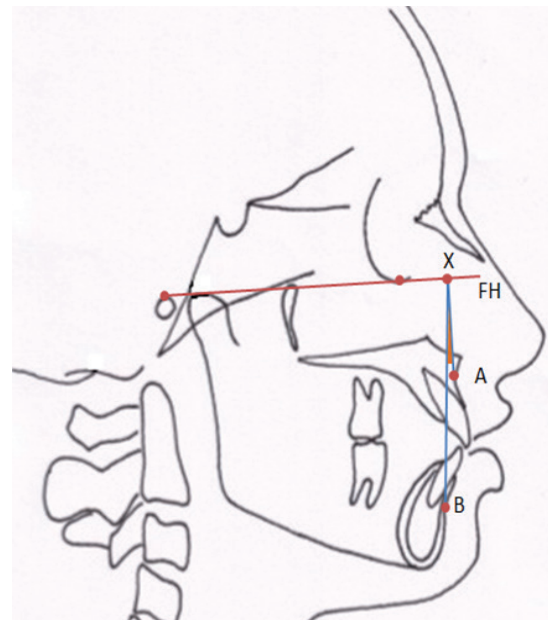

Figure 7: AXB angle

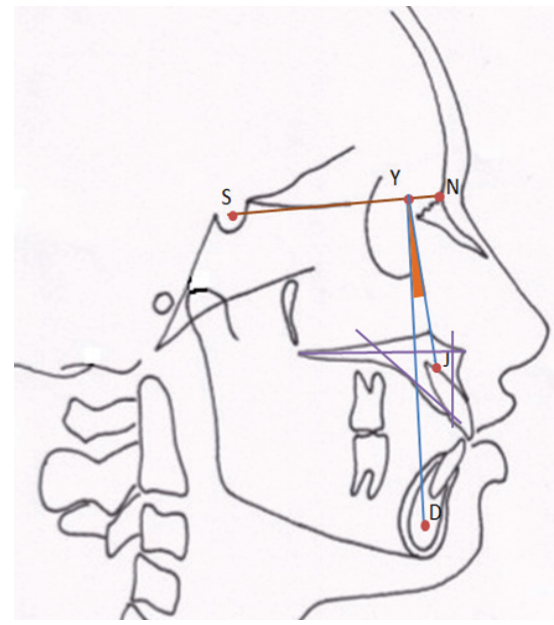

Figure 8: JYD angle 


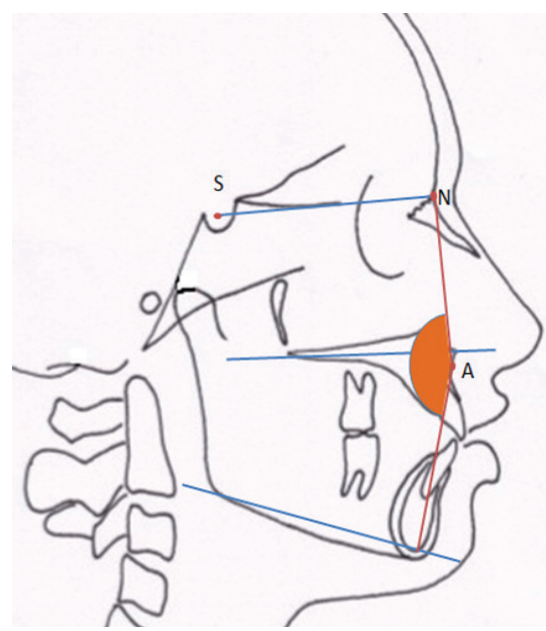

Figure 9: Quadrilateral analysis

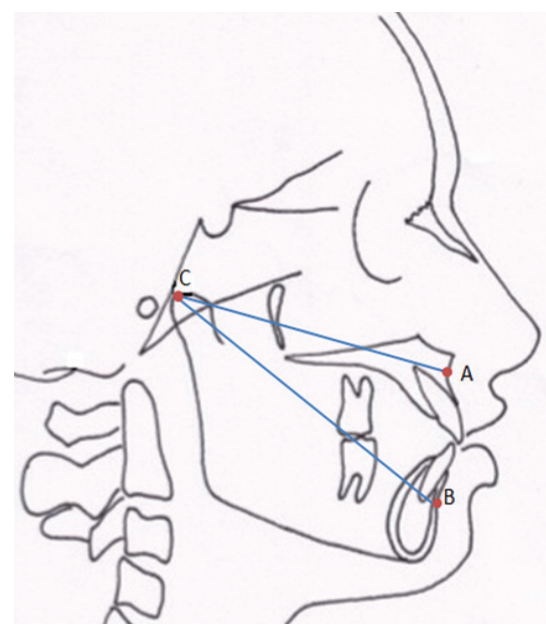

Figure 10: McNamara Maxillo-mandibular Differential

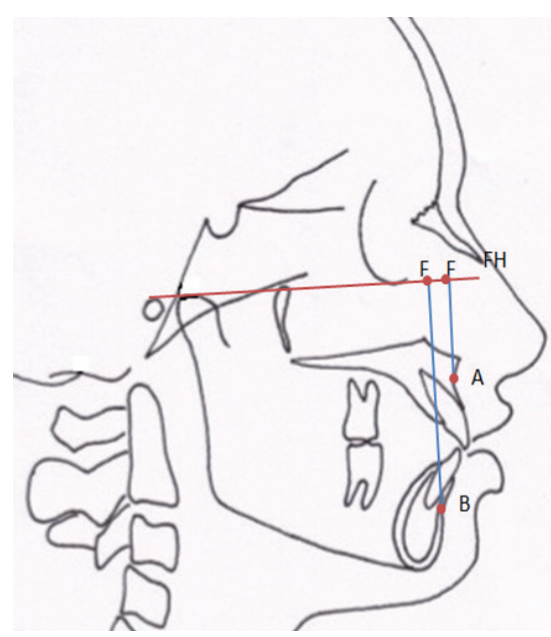

Figure 11: AF-BF Distance
11. Quadrilateral Analysis or Proportional Analysis ${ }^{28}$ Introduced by: Rocco J. Di Paolo (1962)

Based on the concept of lower facial proportionality which states that, in balanced facial pattern there exist a 1:1 proportion between maxillary base length and mandibular base length, also average of anterior lower facial height and posterior lower facial height equals to denture base length

Maxillary base length = mandibular base length $=\mathrm{ALFH}$ $+\mathrm{PLFH} / 2$

Advantage: Offers individualized cephalometric analysis (independent of established angular or linear norms) on patients with or without skeletal dysplasia. It is reliable and accurate method of assessing orthodontic treatment, surgical or combination of both.

\section{McNamara Maxillo-mandibular Differential ${ }^{29}$}

Introduced by: James A. McNamara (1984)

This analysis introduced the composite normative standards derived from the tracings of patient's initial head film compared to established norms from Bolton, Burlington and Ann Arbor samples.

McNamara analysis divides craniofacial skeletal complex into five major sections: maxilla to cranial base, maxilla to mandible, mandible to cranial base, dentition, airway. Maxillo-mandibular differential is calculated by subtracting effective midfacial length from effective mandibular length. Effective midfacial length is calculated from condylion to Point A, effective mandibular length from condylion to anatomic Gnathion. A geometric relationship exists between length of the midface and that of the mandible. Any given effective midfacial length corresponds to a given effective mandibular length.

Ideal maxillo-mandibular differential: Small 20mm, Medium 25-27mm, and Large 30-33mm.

Advantage: Useful in determining actual dimensional variations of midface/mandible, thus giving an idea as to whether a skeletal Class II or Class III problem is positional or dimensional.

\section{AF-BF Distance - The assessment of antero-posterior jaw relationship ${ }^{30}$}

Introduced by: Hong Pu Chang (1987)

AF-BF distance is obtained by projecting perpendiculars from Point $A$ and $B$ to the $\mathrm{FH}$ plane.

The points of contact of perpendiculars onto the Frankfort horizontal plane from Point $A$ and $B$ are labeled $A F$ and $B F$, respectively. The AF-BF distance would be positive when point $A F$ is forward of point $B F$; and the AF-BF reading would be negative if point $A F$ is located behind point BF. The distance of Point $A$ to Nasion vertical (A-NV) defines the horizontal location of the maxilla and the distance of Point $B$ to Nasion vertical (B-NV) determines antero-posterior position of the mandible. The AF-BF distance is equal to the difference between the two values.

Sample: 80 young Chinese (40 males, 40 females), mean age $20-29$ years.

Mean value: $3.4 \pm 2.93$ (male), $3.87 \pm 2.63$ (female)

Advantage: Eliminates Nasion as in Wits appraisal and AFB angle. Not affected by the vertical displacement of Point A or Point B along the Point A or B vertical.

Disadvantage: Inclination of $\mathrm{FH}$ plane may affect the measurement. 


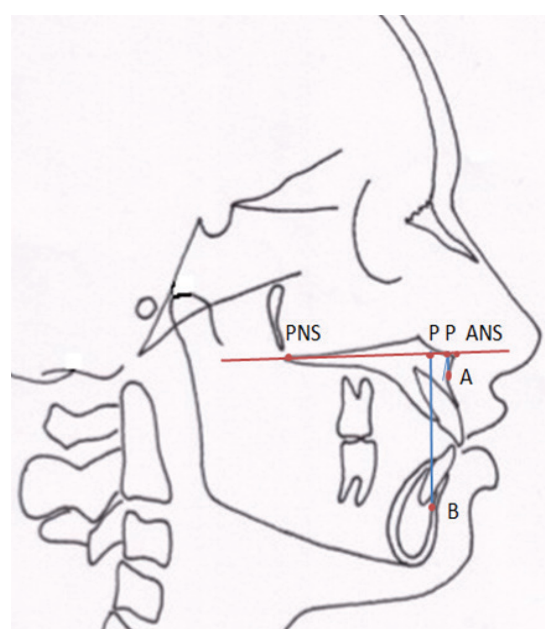

Figure 12: APP-BPP distance

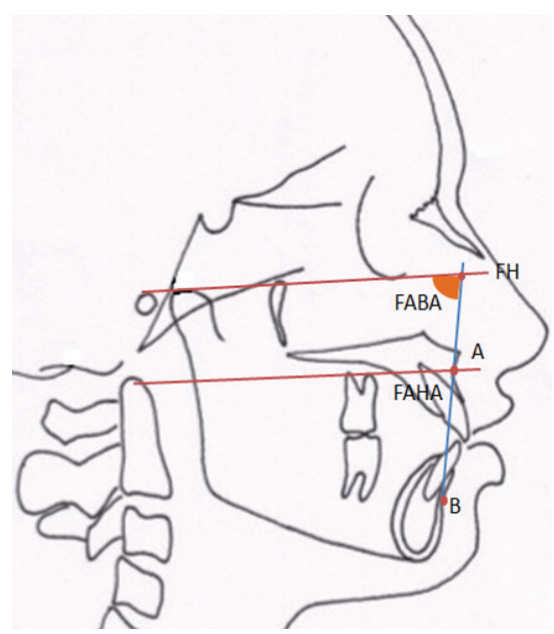

Figure 13: FABA angle

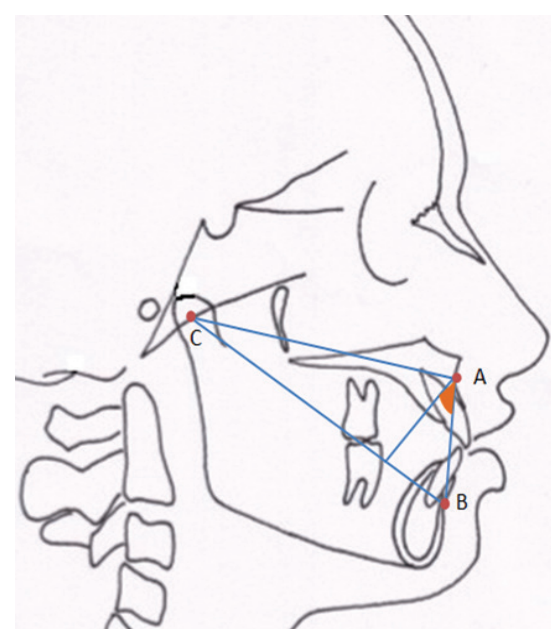

Figure 14: Beta angle

\section{APP-BPP Distance ${ }^{31}$}

Introduced by: Ravindra Nanda and Richard M. Merill (1994)

APP-BPP Distance is the perpendicular dropped from Point $A$ and $B$ on palatal plane.

Sample: White adults

Mean value for normal occlusion: 5.2 \pm 2.9 (female), $4.2 \pm 3.6$ (male). The value increases in Class II and decreases in Class III malocclusion.

Advantage: Analysis is not dependent on variation of Nasion point. Palatal plane is considered to be more stable.

\section{FH to AB Plane Angle ${ }^{32}$}

Introduced by: Sang D. Yang and Cheong H. Suhr (1995).

FABA angle is formed by $\mathrm{FH}$ plane and line $A B$.

Sample: 110 Korean children with normal occlusion.

Mean value: $80.91^{\circ} \pm 2.93^{\circ}$. Angles greater than normal value indicates tendencies towards Class III, and angles lesser than $81^{\circ}$ indicates tendencies towards Class II.

Advantage: FABA is accurate measurement in predicting AP skeletal dysplasia and/ or facial profile than AF-BF or the AFB angle.

\section{Beta Angle ${ }^{4}$}

Introduced by: Chong Yo Baik and Maria Ververidou (2004)

Beta angle is formed between A-B line and Point A perpendicular to $\mathrm{C}-\mathrm{B}$ line. This angle indicates the severity and the type of skeletal dysplasia in sagittal dimension.

Sample: 120 samples, Age group: 15-25 years

Mean value: Skeletal Class I: $28^{\circ}-35^{\circ}$, Class II: $<28^{\circ}$, and
Class III $>35^{\circ}$

Advantage: Rotation of the jaws does not affect this angle.

Disadvantage: It uses Point $\mathrm{A}$ which is affected by orthodontic treatment.

\section{Overjet as a predictor of sagittal dysplasia ${ }^{33}$}

Introduced by: Sanja Zupancic et al (2008)

Determines correlation between overjet value measured on study casts and cephalometric parameters.

Advantage/Disadvantage: Overjet is a good predictor for Class II division 1 malocclusion in sagittal plane; how it is not useful in skeletal Class I and Class II malocclusions. Overjet value permits a significant part of variability of ANB angle, Wits appraisal, and convexity at Point A. However, there is a relatively wide interval variability, which cannot be explained by overjet alone.

\section{Yen angle 5}

Introduced by: Praveen Kumar Neela et al (2009)

Reference points: S (Sella), M (midpoint of premaxilla), $G$ (centre of largest circle that is tangent to internal inferior, anterior and posterior surface of mandibular symphysis)

Mean value for skeletal Class I pattern: $117^{\circ}-123^{\circ}$, Class II: $<117^{\circ}$, Class III: $>123^{\circ}$.

Sample: 75 Mangalore individuals.

Advantage: It uses more stable landmarks and eliminates the difficulty in locating Point $A$ and $B$, functional occlusal plane used in Wits appraisal, and condylar axis used in beta angle analysis. It is not influenced by growth changes.

Disadvantage: Rotation of jaws can mask true sagittal dysplasia. 


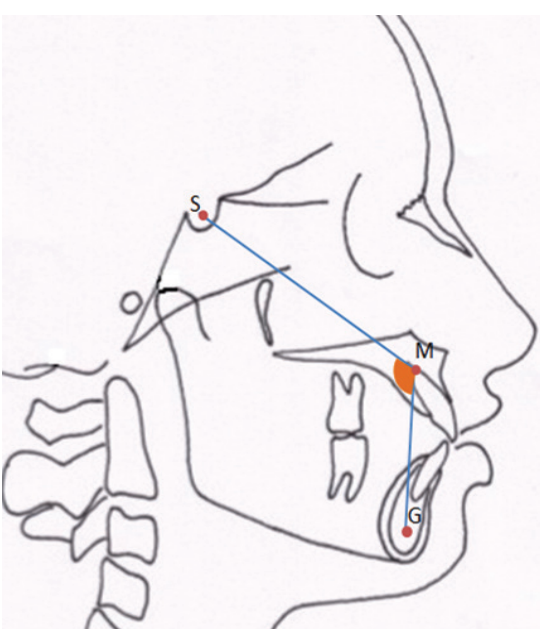

Figure 15: Yen angle

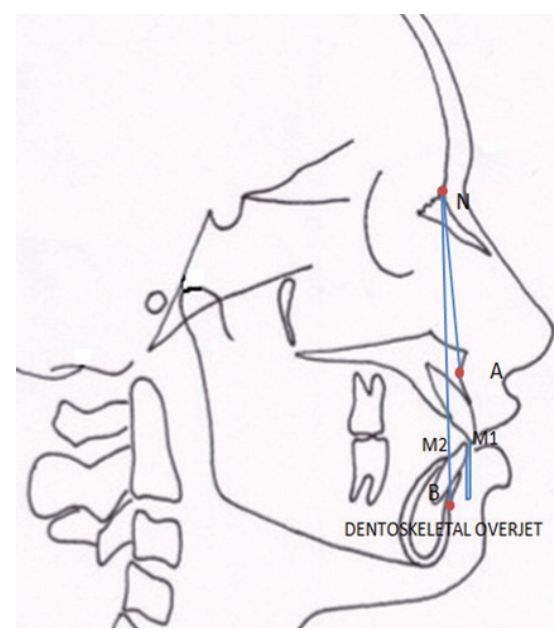

Figure 16: Dentoskeletal overjet

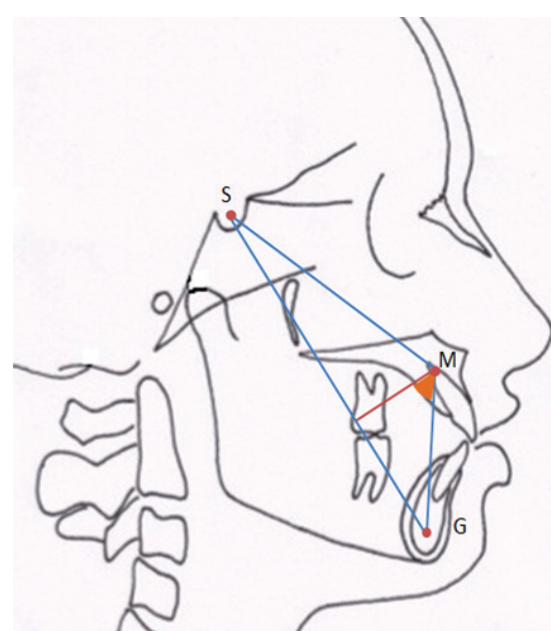

Figure 17: $\mathrm{W}$ angle

\section{Dentoskeletal Overjet ${ }^{34}$}

Introduced by: Al Hammadi (2011)

Dentoskeletal overjet depend on both dentoalveolar compensation for underlying jaw base relation and overjet that remains due to incomplete dentoalveolar compensation as a result of large skeletal discrepancy. Mean value for skeletal Class I: -1 to $2.5 \mathrm{~mm}$, Class II $>2.5 \mathrm{~mm}$, and skeletal Class $\mathrm{III}<-1 \mathrm{~mm}$.

Advantage: It is a linear measurement that has distinct advantages over angular ones; that there are fewer variables affecting its accuracy. Improperidentification of Nasion point in the vertical direction will not affect the final assessment in this measurement. While in ANB angle, Nasion point is the head of the angle that any deviation in its position would directly and principally affect the ANB angle (Taylor, 196912). Compared to Wits appraisal, it depends on landmarks that are easy to identify. Any inclination in the functional occlusal plane will not affect the final reading.

\section{W angle ${ }^{3}$}

Introduced by: Wasundra A. Bhad et al (2011)

$W$ angle is measured between the perpendicular line from Point $M$ to $S-G$ line and $M-G$ line.

Mean value for skeletal Class I: $51-56^{\circ}$, Class $11:<51^{\circ}$, Class III: $>56^{\circ}$.

Advantage: W angle reflects true sagittal dysplasia and is not affected by growth rotations.

\section{Pi analysis ${ }^{35}$}

Introduced by: Santosh Kumar et al (2012)

It consists of two variables, $\mathrm{Pi}$ angle and $\mathrm{Pi}$ linear in the evaluation of antero-posterior skeletal discrepancy. Pi angle is a perpendicular line is drawn from $G$ point to intersect with the true horizontal at $G^{\prime}$, with a further line constructed from $G$ ' to $M$ point.

Sample size - 155 subjects, Mean age 19.7 years.

Mean value: Pi angle for skeletal Class I: 3.400 ( \pm 2.04$)$, Class II: $8.94 \circ( \pm 3.16)$, Class III:

$23.570( \pm 1.61)$

Pi linear in skeletal Class I: $3.40 \mathrm{~mm}( \pm 2.20)$, Class II: $8.90 \mathrm{~mm}( \pm 3.56)$, Class III: $23.30 \mathrm{~mm}( \pm 2.30)$

\section{SAR Angle ${ }^{7}$}

Introduced by: Sonahita Agrawal et al (2014)

SAR angle is measured between the perpendicular line from point $M$ to $W-G$ line and the $M-G$ line.

Sample size: 60 North Indian individuals, Age group: 1325 years.

Mean value: Class I skeletal: $55.98^{\circ}$ (SD 2.24), Class II: $50.18^{\circ}$ (SD 2.70), Class III: $63.65^{\circ}$ (SD 2.25).

Advantage: The Walkers point was found to be stable after the age of five. W-SE remains unchanged in all periods of pubertal growth. ${ }^{36}$ The SAR angle is not influenced by growth, jaw rotations, orthodontic treatment or any other factor previously associated with other angles.

\section{3. $\mathrm{HBN}$ angle ${ }^{6}$}

Introduced by: Harsh Bhagvatiprasad Dave (2015) It is the angle between line perpendicular from point $M$ to $C G$ and $M G$.

Sample: 667 Indian individuals.

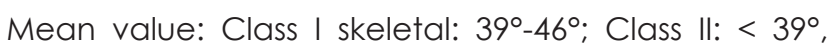
Class III: $>46^{\circ}$ 


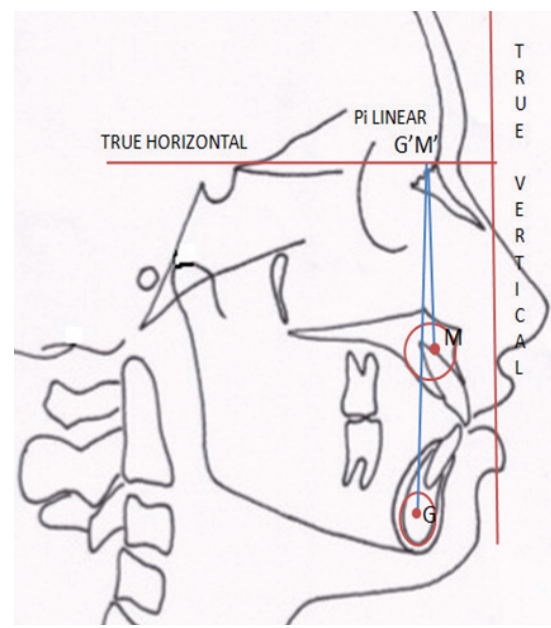

Figure 18: Pi angle and Pi linear

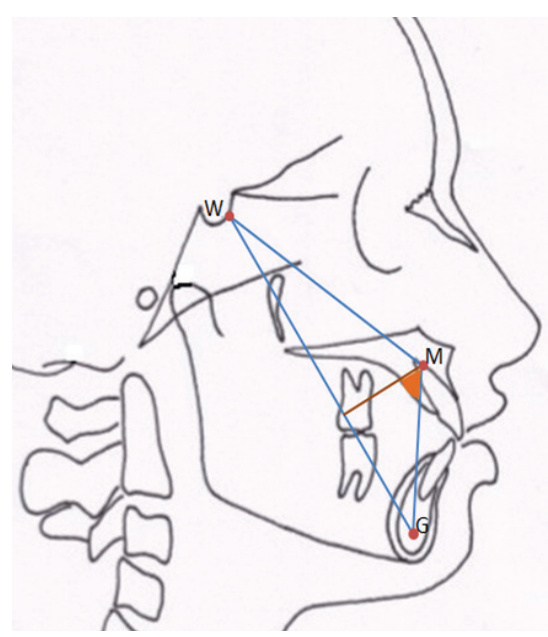

Figure 19: SAR angle

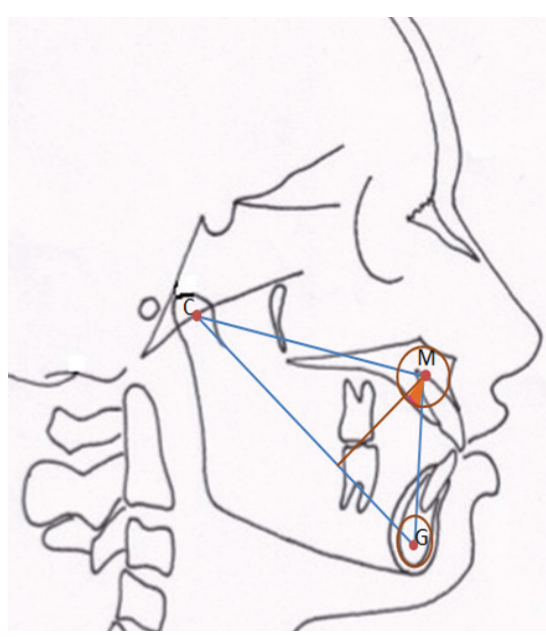

Figure 20: HBN angle
Advantage: HBN angle does not depend on cranial landmarks or functional occlusion plane and Point A and $B$. Remain relatively stable even when the jaws are rotated.

\section{DISCUSSION}

Till date there are many linear parameters like Wylie's method, Wits appraisal, A-D distance, McNamara's maxilla-mandibular differential, AF-BF distance, APPBPP distance and angular measurements ANB angle,
Freeman's AXB angle, FABA, JYD angle, Beta angle, Yen angle and $W$ angle have been developed which have their own advantages and disadvantages. Depending upon the clinician's prospect two or more methods can be used for accurate antero-posterior measurement in orthodontic diagnosis and treatment planning.

\section{REFERENCES}

1. Riedel RA. The relation of maxillary structures to cranium in malocclusion and in normal occlusion. Angle Orthod. 1952;22:142-5.

2. Jacobson A. The 'Wits' appraisal of jaw disharmony. Am J Orthod 1975;67:125-38.

3. Bhad W, Nayak S, Doshi U. A new approach of assessing sagittal dysplasia: The W angle. Eur J Orthod. $2011 ; 1-5$.

4. Baik CY, Ververidou M. A new approach of assessing sagittal discrepancies: The Beta angle. Am J Orthod Dentofac Orthop. 2004;126:100-5.

5. Neela PK, Mascarenhas R, Husain A. A new sagittal dysplasia indicator: The Yen angle. World J Orthod. 2009;10:147-51.

6. Dave HB, GIII V, Rai D, Reddy YNN. The HBN Angle. J Ind Orthod Soc. 2015;49(2):79-84

7. Agarwal S, Bhagchandani J, Mehrotra P, Kapoor S, Jaiswal RK: The SAR Angle: A Contemorary Sagittal Jaw Dysplasia Marker. Orthod J Nep. 2014;4(2):16-20

8. Wylie WL. The assessment of antero-posterior dysplasia. Angle Orthod. 1947;17:97-107.

9. Downs WB. Variation in facial relationship; their significance in treatment and prognosis. Am J Orthod 1948;34(10):812-40.

10. Steiner CC. Cephalometrics for you and me. Am J Orthod 1953;39(10):729-55.

11. Freeman RS. Adjusting the A-N-B angle to reflect the effect of maxlllary position. Angle Orthod. 1981;51 (2):162-71.

12. Taylor CM. Changes in the relationship of nasion, point A and point B, and the effect upon ANB. Am J Orthod 1969;56:143-63.

13. Hussels W, Nanda RS. Analysis of factors affecting angle ANB. Am J Orthod. 1984;85:4-23.

14. Moore AW. Observations on facial growth and its clinical significance. Am J Orthod. 1959;45:399-423.

15. Enlow DH. A morphogenetic analysis of facial growth. Am J Orthod. 1966;52:283-99.

16. Nanda RS. The rates of growth of several facial components measured from serial cephalometric roentgenograms. Am J Orthod. 1955;41:658-73.

17. Binder RE. The geometry of cephalometrics. J Clin Orthod. 1979;13:258-63.

18. Jenkins DH. Analysis of orthodontic deformity employing lateral cephalostatic radiography. Am J Orthod 1955;41 (6):442-52. 
19. Beatty EJ. A modified technique for evaluating apical base relationship. Am J Orthod. 1975;68(3):303-5.

20. Bishara SE, Fahl JA, Peterson LC. Longitudinal changes in ANB angle and Wits appraisal: Clinical implication. Am J Orthod. 1983;84(2):133-9.

21. Richardson M. Measurement of dental base relationship. Eur J Orthod. 1982;4:251-6.

22. Frank S. The occlusal plane: Reliability of its cephalometric location and its changes with growth [Thesis]. University of Oklahoma, Oklahoma; 1983

23. Sherman SL, Woods M, Nanda RS. The longitudinal effects of growth on 'Wits' appraisal. Am J Orthod Dentofac Orthop. 1988;93:429-36.

24. Rushton R, Cohen AM, Linney FD. The relationship and reproducibility of angle ANB and 'Wits' appraisal. Br J Orthod. 1991;18:225-231.

25. Haynes S, Chau M. The reproducibility and repeatability of the Wits analysis. Am J Orthod Dentofac Orthoped 1995;107:640-7.

26. Kim YH, Vietas JJ. Antero-posterior dysplasia indicator: an adjunct to cephalometric differential diagnosis. Am J Orthod 1978;73(6);619-33.

27. Jarvinen S. The JYD angle: A modified of establishing sagittal apical base relationship. Eur J Orthod. 1982;4(4):243-9.

28. DiPaolo RJ, Phillip C, Maganzini Al, Hierce JD. The quadrilateral analysis: An individualized skeletal assessment. Am J orthod. 1983;83(10):19-32.

29. McNamara JA Jr. A method of cephalometric evaluation. Am J Orthod 1984;86(6):449-69.

30. Chang HP. Assessment of antero-posterior jaw relationship. Am J Orthod Dentofacial Orthop 1987;92(2):1 17-22.

31. Nanda RS, Merrilli RM. Cephalometric assessment of sagittal relationship between maxilla and mandible. Am J Orthod Dentof Orthop. 1994; 105:328-44.

32. Sang HD, Suhr CH. F-H to AB plane angle (FABA) for assessment of antero-posterior jaw relationship. Angle Orthod. 1995;65(3):223-31.

33. Zupancic S, Pohar M, Farknik FMO. Overjet as predictor of sagittal skeletal relationships. Eur J Orthod 2008;30(3):269-73.

34. Al-Hammadi. Dentoskeletal overjet: A new method for assessment of sagittal jaw relationship. Aus J Basic App Sci. 201 1;5(9):1830-9.

35. Kumar S, Valiathan A, Gautam P, Chakravarthy k, Jayswal P. An evaluation of Pi analysis in the assessment of antero-posterior jaw relationship. J Orthod. 2012;39(4):262-9.

36. Arat M, Koklu A, Ozdiler E, Rubenduz M, Erdogan B. Craniofacial growth and skeletal maturation: A mixed longitudinal study. Eur J Orthod. $2001 ; 23: 355-61$.

37. Kumar V, Sundareswaran S. Cephalometric assessment of sagittal dysplasia: A review of Twenty-one methods. J Ind Orthod Soc. 2014;48(1):33-41 